\title{
NOTAS SOBRE A DESQUALIFICAÇÃO DO TRABALHO DOCENTE
}

\author{
Fábio Mansano de Mello ${ }^{1}$
}

\section{RESUMO}

O nosso estudo se insere na investigação das relações capitalistas de produção, tendo como objeto de pesquisa a análise do processo de trabalho dos professores do Ensino Médio das escolas privadas; a nossa preocupação é exatamente captar como a dinâmica capitalista interfere e desqualifica tal trabalho.

Palavras-chave: processo de trabalho, desqualificação profissional, trabalho docente.

\section{THE DISQUALIFICATION OF TEACHERS' WORKING PROCESSES}

\begin{abstract}
RESUME
This study investigates the capitalist production relations, and the object of our research is the analysis of private high-School teachers' working processes. Our concern is catching exactly how this capitalist dynamics interferes and disqualifies the referred job.

Key words: working process, professional disqualification, teachers' working
\end{abstract}

\section{Apresentação}

O presente artigo tem por objetivo analisar as transformações ocorridas no trabalho dos professores do Ensino Médio da rede privada, à luz do incremento tecnológico e da organização do trabalho escolar. Para tanto, empreendemos uma investigação das relações capitalistas de produção, compreendendo a escola privada como uma empresa conectada com as leis gerais da acumulação. Realizamos uma pesquisa empírica em algumas escolas particulares de Londrina, que atuam no ensino médio, onde realizamos visitas e aplicamos questionários ao docentes. Defendemos a idéia de que as inovações tecnológicas e as formas de organização gerencial desqualificam o trabalho e a força de trabalho, uma vez que operam sob o mando do capital. $O$ ponto de partida de nosso trabalho é uma releitura dos capítulos históricos

\footnotetext{
Sociólogo, professor do Departamento de Ciências Sociais da Universidade Estadual de Londri-
} na 
de $\mathrm{O}$ capital $^{2}$, especialmente os que tratam da cooperação, manufatura e grande indústria, já que nessa exposição estão firmados os nossos referenciais teóricos acerca da tendência à desqualificação do trabalho mediante a transformação da base técnica. Embora tais transformações pretendam diminuir o custo das mercadorias (inclusive a força de trabalho) e aumentar o tempo de trabalho excedente, na escola não é possivel uma subordinação real do trabalho ao capital; devido às peculiaridades do trabalho docente, a subjetividade nesta atividade persiste. É no interior das relações de produção através da constante divisão do trabalho e da organização gerencial das escolasempresa que constatamos a desqualificação do professor, especificamente na passagem do professor-artesão (escola tradicional) para o professor parcelar (escola capitalista). Nesta última forma de organização escolar fica claro a separação entre concepção e execução dos conteúdos pedagógicos, onde o professor se apresenta como um cumpridor de tarefas impostas pelos cursos apostilados.

\section{O processo de trabalho docente}

Podemos associar a gênese do processo de desqualificação do trabalhador da educação à passagem da chamada escola tradicional para a escola capitalista. Tal movimento deflagrou-se não apenas devido à divisão do trabalho e à incorporação de tecnologia, mas também porque estava atrelado ao impulso do capital em valorizar-se em áreas ditas não-produtivas. Na concepção pedagógica de tipo tradicional podemos destacar a inexistência de divisão do trabalho; o professor-artesão é o responsável pela concepção e execução de seu produto (aula) e detém pleno controle desse saber. Segundo $S^{3}{ }^{3}$, a grande mudança no processo produtivo escolar é a passagem desse trabalho artesanal para o trabalho parcelar da escola capitalista, que determina sua nova organização no interior dessas instituições:

O resultado do desenvolvimento da divisão do trabalho educacional é a parcelarização do trabalho pedagógico ou desagregação da autoridade pedagógica do professor artesão. Tal desagregação significa, ao mesmo tempo, a exploração do saber concentrado no professor e sua localização no capital ou nas empresas estatais. É dessa característica que resulta a constatação empírica da "desqualificação" ou "incompetência" do professor. (Sá, 1986, p. 24)

\footnotetext{
${ }^{2}$ Marx, K. O capital. Critica à economia política. São Paulo: Abril Cultural, 1982. Nesta apresentacão suprimimos as passagens da Seção IV.

3 Sá, N. P. O aprofundamento das relaçōes capitalistas no interior da escola. In: Cadernos de Pesquisa, São Paulo (57): 20.29, maio, 1986
} 
A ampliação da divisão do trabalho e o avanço tecnológico abrem espaço para a instauração de relações estritamente capitalistas no interior das escolas. O trabalho dos professores, que outrora gozava de vasto prestígio e demandava status na sociedade, passa a ser dessacralizado e atirado aos pés da concorrência capitalista como qualquer outra mercadoria. Para Franco ${ }^{4}$,

A divisão técnica do trabalho pedagógico se dará em um momento de plena expansão do capitalismo monopolista, que tende a taylorizar e fragmentar o trabalho em praticamente todos os domínios da vida social. A escola, como parte integrante e inseparável da totalidade social, não poderia ser exceção a esse imperativo do capitalismo. Ao contrário, a escola passa reproduzir dicotomias muito parecidas com aquelas encontradas no trabalho fabril: separação entre alguns que pensam, planejam e concebem o trabalho pedagógico (especialistas) e a maioria que meramente executa o trabalho pensado por outros (professores). O que se busca, com isso, é uma maior racionalidade e eficiência do processo de ensino-aprendizagem, mas o que se consegue é um esvaziamento do fazer pedagógico. (p. 65-6)

Essas imposições transcendem a noção do "bom professor" ${ }^{5}$, já que no momento da venda da força de trabalho o controle do processo educacional está nas mãos do empresário capitalista. Esta nova organização do trabalho vai matizar as relações de trabalho destes profissionais e seus desdobramentos devem ser cuidadosamente investigados. As inúmeras transformações ocorridas no processo de trabalho escolar têm imposto aos professores um ritmo específico no seu dia a dia. A racionalização da produção escolar, cujas técnicas são especialmente advindas da administração escolar norte-americana ${ }^{6}$, têm criado uma enorme massa de trabalhadores escolares que não freqüentam as salas de aula. Esses burocratas do ensino atuam no sentido de organizar o material didático, determinam o conteúdo das disciplinas, o modo através do qual esse conhecimento deve ser transmitido ao aluno, bem como as técnicas apropriadas para a assimilação do mesmo. Isso demonstra que as escolas se organizam em moldes empresariais e seguem os padrões industriais de gerência sobre o processo produtivo. Conforme Wrobel ${ }^{7}$ :

\footnotetext{
${ }^{4}$ Franco, A C. C. A escola do trabalho e o trabalho da escola. Sãp Paulo: Cortez, 1988.

5 Conceito utilizado por Basso (1998), que assim o define: "São professores com uma formação adequada que inclui a compreensão do significado de seu trabalho e que, encontrando melhores condições objetivas ou lutando muito por elas, e, alguns casos, contando com apoio institucional, concretizam uma prática pedagógica mais eficiente e menos alienante." (Op. Cit, p. 29)

' cf. Apple, M. W. Trabalho docente e textos: economia politica das relaçōes de classe e de gênero em educação. Porto Alegre: Artes Médicas, 1995.

7 Wrobel, V. Escolas públicas e privadas: uma leitura sociológica de sua dinâmica organizacional. In: Revista de Ciências Sociais, Rio de Janeiro, Vol. 27, n 2, 1984, p. 215-232.
} 
Segundo o paradigma dominante das teorias organizacionais, a estrutura formal de uma organização é o elemento mais efetivo na coordenação e controle de suas atividades internas. É nela que as posições são definidas, os cargos distribuidos, as funções delimitadas. Em síntese, ela é responsável pelo controle da qualidade do produto, bem como pelo processo de produção. Em outras palavras, a estrutura é o elemento estratégico na integração dos componentes de uma organização, bem como na maneira como os recursos são distribuídos e utilizados na consecução dos objetivos: no processo de integração, controlando e coordenando as atividades e ao mesmo tempo buscando os meios mais adequados a partir de uma política de avaliação do ajuste entre meios e fins. (p. 216)

Essa estrutura organizacional pode ser constatada através dos organogramas dos colégios, onde são definidos os cargos e as funções dos seus trabalhadores. Ocorre, obviamente, uma variação de escola para escola, no entanto podemos notar a seguinte divisão: - Diretoria Geral, responsável pela administração geral; - Coordenadoria Pedagógica, responsável pela qualidade do trabalho docente, atua assessorando os professores; - Coordenadoria de Eixos, os profissionais se dividem nas áreas do conhecimento (humanas, exatas e biológicas) e são responsáveis pelo planejamento, execução e qualidade das aulas; - Coordenadoria de Informática, responsável pela utilização das técnicas pedagógicas (video, computador, power-point) pelos professores bem como assessorá-los quando preciso; - Bibliotecário, organiza e disponibiliza todo o material de pesquisa da biblioteca; Secretário Geral, responsável pela documentação do colégio e do aluno.

Nas escolas estudadas, o ensino médio possui um coordenador responsável; sua tarefa é fazer com que os cursos sejam ofertados dentro do prazo (afinal de contas as apostilas estão divididas em módulos que demandam uma destreza peculiar dos professores) e supervisionar o trabalho dos mesmos. Este discurso, porém, possui outros desdobramentos. O papel da supervisão tem seu início com o advento da empresa capitalista, e seu papel era promover o maior lucro com o mínimo de tempo. Se nos primórdios da acumulação a tarefa do supervisor era impedir que os operários quebrassem as máquinas, com o taylorismo passou a cronometrar os tempos das atividades fabris e exigir dos trabalhadores que a mesma tarefa pudesse ser executada em menos tempo: permanece, portanto, o "sentido" de sua função, maximizar os lucros do empresário. Vejamos esta passagem de Gadotti, ${ }^{8}$ em que o autor associa a supervisão à uma militarização do ensino:

${ }^{8}$ Gadotti, M. Educação e poder. Introdução a pedagogia do conflito. São Paulo: Cortez, 1998. 
A ideologia industrial penetrou na escola, transformando-a em empresa. E a escola não só não resistiu como também passou a utilizar-se do dicionário economicista. A supervisão escolar é um exemplo, embora tente desvencilhar-se de suas origens, ultrapassando sua concepção fiscalizadora para formular uma concepção mais integradora, coordenadora. Mesmo assim, não adianta mudar o vocabulário se não for mudada a ideologia. p. 106)

Nas escolas analisadas, algumas adotam apostilas de outros cursos, uma adota livros didáticos e outras possuem material apostilado próprio. Nos cursos apostilados, as disciplinas são organizadas bimestralmente, cabendo ao executor da tarefa de transmissão dos conteúdos cumprir sua missão sem exceder o tempo previamente determinado para tal. Se isso ocorrer, o professor deverá marcar aulas extras para 'colocar a matéria em dia' e não comprometer o andamento do próximo bimestre (ou próxima apostila). Geralmente as escolas privadas possuem o sistema de monitorias, que consiste em auxiliar o trabalho de sala de aula, ou mesmo atuando como 'tira-dúvida' (as disciplinas com maior procura por parte dos alunos são as da área de ciências exatas: matemática, física e química). Constatamos três casos dessa atividade: 1) o próprio professor determina o horário e dá assistência aos alunos. 2) o aluno que mais se destaca na disciplina é convidado a realizar esse trabalho, sempre sob a coordenação do professor responsável pela matéria, e em troca obtém abatimento que varia de 5 a $15 \%$ no valor da mensalidade. 3 ) a escola contrata alunos de graduação da matéria em pauta, ou de áreas afins, e realiza essa tarefa pela qual recebe por hora.

Devido às exigências do cumprimento do programa, grande parte dos professores leciona seguindo à risca os conteúdos das apostilas; dentre os professores entrevistados, alguns utilizavam textos de apoio em sala de aula, outros apenas indicavam bibliografia complementar e outros recorriam ao laboratório de ciências para "incrementar" a aula. No geral, e o que nos interessa aqui, é que todas as atividades são rigorosamente controladas pela direção, desde o trabalho em sala, a utilização de recursos pedagógicos diversos até o desempenho do aluno, mensurado por avaliações bimestrais que, nos cursos apostilados, são emitidas provas lacradas provenientes da central da empresa, o que impele o docente a seguir à risca os conteúdos. Perguntamos aos professores que exercem a profissão há mais tempo sobre a diferença entre trabalhar com livros didáticos e com apostilas. Segundo eles, o livro é um material mais completo, que possui melhor seqüência dos assuntos a

\footnotetext{
9 Motta, C. E. S. IndustriA cultural e o sistema apostilado: a lógica do capitalismo. In: Cadernos Cedes, ano XXI, N. 54, agosto/2001
} 
serem tratados. O livro desperta a atenção dos alunos, devido ao formato, às cores, às ilustrações, etc.; é essa densidade que acaba sendo um "ponto desfavorável" à sua utilização: a falta de tempo hábil para cumprir as lições. Atentemos para esse depoimento: "Com o livro o professor tinha mais autonomia em relação à sala de aula, podendo interligar os fatos históricos e através dos textos promover discussões em grupo. Já com as apostilas isso não é possivel, pois ela é compartimentada e presa ao binômio 'texto-exercícios' " (Professor de História). A apostila oferece o curso dividido em etapas (bimestres) que significa maior praticidade, denotando adequação aos propósitos da empresa-escola: maior número de informação possível para o cliente, além de movimentar um mercado lucrativo. Motta ${ }^{9}$ faz uma crítica aos cursos apostilados, afirmando sua adaptação social e sua inserção no contexto da Indústria Cultural; aponta a deficiência da divisão das disciplinas em cadernos e a séria impressão causada pela apostila de que todo conteúdo a ser alcançado está nas suas páginas:

Na escola, o sistema apostilado, como mais uma mercadoria inserida no contexto da Indústria Cultural, promete oferecer um ensino organizado, prático e racional. Mas, fragmentando o conhecimento, incapacita o individuo de compreendê-lo de maneira global, incluindo causas, processos, conseqüências, contextos etc. A quebra da unidade impede a ação reflexiva e transforma-se em instrumento de dominação. Reproduz a ideologia de setores privados e do próprio Estado, preparando o indivíduo quase que exclusivamente para o vestibular, afastando-o da possibilidade de um ensino e de uma educação emancipadores, bem como do conhecimento, da aquisição e do usufruto da cultura. Mais do que isso, impede-o de refletir sobre sua condição de cidadão e de optar com maior liberdade por seu destino. (p. 88)

Na maioria dos casos estudados o professor prepara as aulas em casa. Devido à agitação do trabalho semanal, tal tarefa exige o final de semana desses trabalhadores, que realizam uma atividade não-remunerada. A preparação das aulas exige um trabalho de pesquisa, mesmo porque a apostila carece de conteúdo; um dos recursos mais usados pelos professores é a internet, que por sua vez demanda um investimento privado dos mesmos: é necessário possuir um micro-computador e arcar com as despesas do provedor. "A questão da preparação das aulas é muito curiosa. Não é questão de ler e reler a matéria antes da aula. É uma coisa mais complexa que envolve toda a sua formação e a maneira de como permanecer atualizado. E isso requer tempo e dinheiro. $\mathrm{O}$ professor, pelo menos o bom professor, não trabalha unicamente na sala de aula; a cabeça não pára de pensar, de refletir. Você está assistindo a um filme e nota que pode levantar uma questão para os alunos, você está navegando e descobre um site interessante com o assunto 
de sua matéria, você assina e lê jornais e revistas para trazer questões atuais para a sala, quero dizer, isso tudo deve partir do professor e esse custo todo não está embutido nas horas/aula." (Professor de Geografia)

Devido ao fato de trabalhar com várias turmas, e muitas vezes em várias escolas, o professor ministra as mesmas aulas, o que demonstra a rotinização do trabalho, uma transmissão de conteúdos que ocorre 'mecanicamente', no sentido de maximizar o seu tempo de trabalho. É essa parcelarização das atividades docentes que nos leva a pensar na taylorização do ensino. $O$ conteúdo programático do ensino médio apresenta as disciplinas divididas em distintas partes, chamadas de "frentes". No caso da disciplina Língua Portuguesa, encontramos a seguinte apresentação: gramática, literatura e redação. Na matéria História, bem como na Geografia, a divisão é feita entre "geral" e "Brasil". Temos Química orgânica e inorgânica. Na Biologia, a distinção é feita entre botânica, zoologia e citologia. Cada frente demanda um professor específico, que se encarregará de ministrar o curso ao longo do ano. As duas ou mais frentes devem se desenvolver simultaneamente, mas se no final do bimestre alguma se adiantar, geralmente cede algumas aulas para que a outra frente se recomponha. Caso o professor não cumpra essas atividades, a reposição é a saída (inclusive com a utilização de monitorias). Acreditamos, portanto, haver indícios de uma especialização do trabalhador. Com os cursos oferecidos em módulos, divididos nas diferentes apostilas, as empresas do ensino controlam o tempo de trabalho dos professores, que precisam enxugar o conteúdo das disciplinas para alcançarem o produto final de suas atividades: a aprovação dos alunos nos concursos vestibulares. São essas condições impostas pela divisão do trabalho que hoje prescindem do professorartesão, que preparava todo o curso a ser ministrado e tinha pleno controle sobre o mesmo. Aqui ocorre o inverso. A "melhor engrenagem", do ponto de vista do capital, é o trabalhador fragmentado que, no nosso caso, prescinde até mesmo da formação mínima, já que muitos colégios contratam alunos de graduação para compor o seu quadro de funcionários. Constatamos uma taylorização do processo de trabalho docente, que têm suas atividades cindidas e centradas na separação do planejamento e execução. Segundo Apple, ${ }^{10}$

O conteúdo programático é dividido em vários módulos exigindo a "especialização" do professor, que com o passar do tempo perde o controle sobre o conhecimento mais abrangente de sua disciplina. Isso leva-o à desqualificação profissional,

\footnotetext{
${ }^{10}$ Apple, M. W. Afinal, de quem é este currículo? In: Conhecimento oficial: a educação democrática numa era conservadora. Petrópolis: Vozes, 1997.
} 
já que exercem funções previamente estabelecidas e têm sua atividade intelectual deformada pelos ditames da nova gerência educacional. "Ao invés de professores profissionais, bastante preocupados com o que fazem e com as razões de suas ações, poderemos ter executores alienados de planos alheios" (p. 182).

A idéia da desqualificação está, por sua vez, ligada à intensificação do trabalho. São inúmeras as ocorrências que levam a esse fenômeno, das quais podemos destacar: profissionais mal remunerados que precisam trabalhar em várias escolas, docentes que ministram mais de uma matéria (por exemplo, o professor que leciona história num colégio e geografia noutro), professores que assumem cargos de coordenadoria de área sem deixar a sala de aula, necessidade de capacitação frente às novas tecnologias de educação, etc. Os resultados desse processo não poderiam ser diferentes:

\begin{abstract}
A intensificação leva as pessoas a "tomar atalhos" de modo que apenas é feito o que é "essencial" em relação à tarefa a ser imediatamente executada. Isso força as pessoas a confiarem de forma crescente em "especialistas" para dizer-lhes o que fazer e elas começam a perder a confiança nas próprias habilidades que desenvolveram ao longo dos anos. No processo, a qualidade é sacrificada pela quantidade. O trabalho bem feito acaba sendo substituido por trabalho que simplesmente se cumpre (APPLE, p. 184).
\end{abstract}

Essas implicações no processo produtivo escolar, aliadas ao incremento da base técnica, têm desfigurado o trabalho docente, que tem resistido a certas facetas ditas "progressistas" e tentando manter o domínio sobre o processo produtivo. A escola privada, porém, tem se constituído num locus privilegiado de apresentação e difusão de novas mercadorias: cursos apostilados, pacotes multimídia, tele-aulas, computadores, etc. Em suma, as empresas organizam o ensino (e não raro disponibiliza o material confeccionado em gráficas próprias) e os professores executam as determinações impostas pela "nova gerência" Com o crescimento do empreendimento, a empresa-escola começa a investir capitais de formas distintas em busca do aumento da extração de mais-valia. Vejamos o caso deste colégio. Até o final da década de oitenta, a escola utilizava material apostilado de outra empresa; a partir de 1987 o colégio adquiriu um parque gráfico próprio, e dois anos mais tarde já produzia o próprio material pedagógico. Hoje possui uma editora que é responsável pela comercialização

\footnotetext{
1 Um entrevistado nos informou que determinada apostila fornece folhas avulsas no caderno do professor, sugerindo que o docente utilize este ou aquele exemplo para ilustrar a aula, bem como indica quais exercicios deverão ser feitos em sala de aula ou fora dela. É verdade que são sugestões, todavia a preocupação por parte dos professores quanto ao prazo do curso os impele a acatar determinadas resoluções.
} 
de todo conteúdo pedagógico para o colégio e mais de cem escolas conveniadas. Outro exemplo é o investimento na área da alimentação. Em 1991 o grupo resolveu assumir a cantina do colégio, até então terceirizada. Surgia então uma nova empresa, que produz em uma cozinha semi-industrial o lanche para os alunos da Educação Infantil, além de salgados, bolos e sucos; esse ramo da empresa está presente também nas escolas conveniadas. Notamos assim que os capitais dessas empresas não são investidos apenas no processo produtivo, como é o caso da informatização do ensino, mas também vão ampliando seu campo de atuação. Não raro os casos em que escolas-empresa do Ensino Médio se expandem de tal forma que criam suas próprias Universidades. Como em qualquer outro setor, as mudanças são acompanhadas por um certo grau de descontentamento por parte dos profissionais. Especialmente em relação à tecnologia, que fascina muitos e desencanta outros tantos, deve-se notar a importância dos recursos (no caso a informática) e atentar como esses instrumentos são utilizados no conjunto do processo escolar. Vejamos como as novas tecnologias afetaram o trabalho no interior das escolas e como os professores têm a sua atividade "modernizada" através do incremento das novas técnicas pedagógicas. $O$ processo de informatização das escolas, bem como a utilização dos mais variados recursos educacionais (antena parabólica, cd-rom, PowerPoint) deve ser entendido dentro de um contexto mais amplo do desenvolvimento das forças produtivas, para que não seja reproduzida uma imagem apologética do sistema que, através de novas técnicas, confira uma roupagem de plena eficiência às instituições que as utilizam. O inverso também preocupa: as escolas que não fazem uso de tais recursos não devem ser estigmatizadas como ultrapassadas. Para Enguita, ${ }^{12}$

O nivel tecnológico alcançado na atualidade já permite dar o salto para a satisfação total ou quase totalmente individualizada da necessidade de ensino. Basta pensar nas possibilidades, para além dos tradicionais livros, que oferecem as fitas cassetes, os videos-cassetes, as fotocopiadoras, os vídeo-discos, a televisão por cabo, os microcomputadores ou os terminais conectados a um computador central ou a uma rede. Quando a tecnologia permitir não apenas produzir essas coisas, mas produzi-las a preços que permitam sua venda massiva, estarão lançada as condições para o assalto final do setor de ensino (p. 284)

Convém aqui uma reflexão acerca das possibilidades de facilitação do processo cognitivo através da utilização de tecnologias bem como do

12 Enguita, M. F. Trabalho, escola e ideologia: Marx e a crítica da educação. Porto Alegre: Artes Médicas, 1993 
balizamento de tais técnicas no que tange a um "assalto final" da educação. Afirmar simplesmente que a Internet e a utilização dos microcomputadores no trabalho escolar significa um avanço em termos de técnicas pedagógicas parece ser um discurso ideológico. Não pretendemos negar a contribuição em termos de informação e agilidade operacional que esses recursos proporcionam, todavia a idéia de um alto grau de desenvolvimento tecnológico na educação não pode ser analisada de forma unilateral. A começar pela distinção entre informação e conhecimento: a própria rede internacional de computadores não é uma fonte totalmente segura em termos de confiabilidade do seu conteúdo. Se acreditamos na premissa de que a educação escolar atua na formação não só de profissionais para o mercado mas também na formação de homens capazes de refletir e interferir nas questões de seu tempo, não serão as máquinas os principais atores desse processo. Eis aqui uma peculiaridade do trabalho escolar, que é exatamente como a informática atua nesse processo. Ressaltemos que tratar de assuntos como informática e novas tecnologias exigem certos cuidados; tornou-se modismo aliar tais conceitos à modernidade e inserção no mercado de trabalho. As informações são processadas e avaliadas num ritmo alucinante onde o presente traz consigo todas as resoluções pertinentes a um mundo efêmero e que o passado é obsoleto. É preciso atentar como os homens aparecem nessa corrida infindável em busca do moderno e como tais incrementos tecnológicos condicionam, no nosso caso, o trabalho docente.

Nos colégios estudados constatamos diversas formas de contato dos professores com as novas tecnologias; não é nossa intenção descrever o funcionamento de cada unidade escolar, mas sim captar as especificidades de cada um deles. Dentre os colégios que contam com laboratórios de informática, trataremos de dois casos, os quais denominamos Escolas A e B. A Escola A implantou o laboratório de informática em 1998 e conta hoje com computadores e televisores; segundo a responsável pela unidade, o mesmo ainda é pouco utilizado pelos professores do ensino médio, que alegam ter pouco tempo disponivel para preparar tais aulas e dar conta dos conteúdos das matérias em curso. As aulas no laboratório são portanto escassas e quando ocorrem são elaboradas por um técnico que auxilia o docente. "O professor precisa totalmente do meu auxílio; ele tem domínio do conteúdo da disciplina, mas é seu objetivo ter domínio dos programas e de outras técnicas, como o power-point" (técnico de informática). Vale ressaltar que em ambos os colégios o técnico também tem conhecimentos pedagógicos, o que resulta, segundo eles, num maior aproveitamento dos conteúdos. Diferentemente da Escola A, a Escola B possui um sistema de aula virtual, a chamada aulanet. Todos os professores do ensino médio preparam tal material antes da prova bimestral, que fica disponível na 
home page do colégio. A central de informática foi implantada no ano de 2002 e o colégio oferece cursos de capacitação para o seu quadro docente. A instituição mantenedora do colégio também atua no ensino superior e portanto tem ao seu dispor não apenas amplas instalações como grande número de equipamentos, bem como técnicos que auxiliam os professores na confecção das aulas. Podemos constatar certa resistência dos professores em relação à utilização desses recursos, seja devido à falta de conhecimento de informática, seja pela falta de tempo; falta tempo não só por trabalharem com numerosas turmas e em vários colégios, como também para ministrar todo o conteúdo programático visando o vestibular.

Num espaço curto de tempo esse professor é obrigado a se adaptar numa escola onde ele não só utiliza quadro negro e giz, mas também deve dominar uma nova estrutura de equipamentos, onde sua tarefa pode ser até mesmo virtual. $O$ docente em questão, que na sua formação acadêmica não recebeu orientação para tais atividades, têm suas atribuições profissionais aumentadas, o que não redunda num acréscimo salarial: ganha, sim, uma intensificação do seu trabalho. Devemos salientar que muitos dos professores entrevistados atentam para um ponto importante no que tange a utilização das tecnologias, em especial o computador: a procura dos alunos. Grande parte deles estão familiarizados com o micro, cd-rom, Internet, incentivados em casa desde cedo, e portanto acabam exigindo das escolas um processo de aprendizagem que contenham núcleos informatizados. Não significa ensinar unilateralmente os conteúdos através da informática, mas incentivar e aguçar a ligação das novas técnicas com o tema estudado: exemplo disso são as aulas de Química elaboradas no programa Power-Point onde são mostradas imagens em terceira dimensão. As novas tecnologias da educação devem ser compreendidas enquanto um facilitador da prática pedagógica e não um agente auto-suficiente portador de conhecimento. $\mathrm{O}$ caráter crucial de sua utilização é a forma mercantil que assume e conseqüentemente uma distinção hierárquica que poderá acarretar nos professores "capacitados" e "nãocapacitados" quanto às práticas informacionais:

Os meios tecnológicos educacionais proporcionam possibilidades imensas na forma de se ensinar e no trabalho docente, mas seu uso não deve implicar num processo ainda maior de segmentação dos docentes, pois dessa forma a qualidade do ensino fica prejudicada, mantendo-se e mesmo agravando-se as disparidade existentes (ARRUDA, p. 307) ${ }^{13}$

\footnotetext{
${ }^{13}$ ARRUDA, E. Trabalho docente e novas tecnologias educacionais: virtualidade positiva ou realidade conflitante? In: PIMENTA, S. M., CORREIA, M. L. (orgs) Gestão, trabalho e cidadania: novas articulações. Belo Horizonte: Autêntica/ CEPEAD/ FACE/ UFMG, 2001.
} 
É neste sentido que afirmamos que a desqualificação profissional através da tecnologia não pode ser analisada de forma linear. Se numa escola ouvimos do supervisor que alguns professores foram demitidos por não se adequarem às novas tecnologias, outros docentes afirmam que os requisitos para operar um microcomputador, por exemplo, são mínimos: "não tem segredo". Acreditamos que a desqualificação está articulada ao conjunto das relações de produção e é no interior do processo de trabalho que, ao lado de outras formas de subsunção no capital, o trabalhador perde suas habilidades.

Embora submetidos a uma desgastante rotina, muitos professores (que não raro se identificam como trabalhadores intelectuais) vivem uma condição profissional dúbia, que Enguita ${ }^{14}$ chama de ambigüidade na docência: embora submetidos à burocracia educacional muitos desses profissionais realizam tarefas que demandam alta capacitação, conservando assim o controle sobre o processo produtivo. De outro lado, constatamos cada vez mais a parcelarização deste trabalho e a total separação entre concepção e execução. Essa relação terá importantes reflexos na organização de classes destes profissionais.

Segundo informações do Sindicato dos Professores das Escolas Particulares de Londrina e norte do Paraná (SINPRO), a instituição possui 560 profissionais sindicalizados. Oferece cursos e palestras para os filiados, além de manter uma biblioteca e editar um jornal mensal com assuntos de interesse da categoria. Em relação às novas tecnologias, perguntamos se os professores têm demonstrado algum tipo de resistência quanto à implantação das mesmas. Segundo um dos diretores da instituição, o desenvolvimento tecnológico é uma realidade e não há como o professor ignorar a utilização destas tecnologias nas atividades docentes. Parece-nos, portanto, dificil tratar de formas de resistência num mercado de trabalho altamente competitivo onde a capacitação (do ponto de vista do capital) é condição primordial para permanecer no mercado. Como o professor "tem que ter um computador", o sindicato mantém um convênio com a Caixa Federal no sentido de conseguir financiamento para a compra desses aparelhos. Constatamos em nossa investigação que grande parte dos profissionais atuam em escolas de diferentes niveis (unidades que possuem um ritmo "mais puxado" e outras um ritmo mais lento) e de natureza diferentes (escolas públicas e privadas). Além da diferença salarial, onde o professor da iniciativa privada recebe por horasaula e o profissional da escola pública recebe por carga horária (20 ou 40

\footnotetext{
${ }^{14}$ Enguita, M. F. Ambigüidade da docência: entre o profissionalismo e a proletarização. In: Revista Teoria E̊ Educação. V. 4, $1991 \mathrm{~b}$.
} 
horas semanais) não só por atividades em sala de aula, as relações socias que os mesmos travam são distintas. Na rede particular, as relações são mercantis, a atividade realizada é trabalho produtivo, que gera a mais-valia e faz com que esse trabalhador seja um proletário. Ocorre que o mesmo docente pode executar trabalho idêntico na escola pública, realizando um trabalho improdutivo, já que é pago com fundo público e não com capital. Na atividade docente as relações não são puras. $O$ docente da escola pública, por exemplo, que tem o seu trabalho regido pelo Estatuto do Magistério, possui uma série de aparatos legais diferenciados do professor da escola privada, onde vige a C.L.T.. No ensino público o trabalhador tem direito a vários tipos de licenciamento, todos remunerados integralmente; na escola particular as licenças são menos freqüentes, seguindo as normas das leis trabalhistas. $\mathrm{O}$ funcionário público tem direito ainda à licença-prêmio, que lhe concede noventa dias de gratificação caso o mesmo não apresente nenhuma falta ou licença nos últimos cinco anos. Se ocorrer algum sério problema de saúde com o profissional concursado da rede pública, que o impeça de exercer sua atividade, existe a possibilidade do remanejamento e da readaptação em outra função, sem prejuízo de salário, o que não ocorre na escola privada. Nesta instituição o trabalhador goza trinta dias de férias, sendo geralmente três semanas em janeiro e uma em julho; na escola pública ocorre, além das férias normais de trinta dias, dois recessos escolares, no meio e no final do ano.

No intuito de complementar o salário, professores trabalham numa extensa jornada, incluindo várias escolas, públicas e privadas, que chega até a 60 horas semanais. A questão da faixa etária dos professores do Ensino Médio está ligada com a alta rotatividade dos profissionais: "eles não ficam velhos". As escolas particulares exigem muito do trabalhador docente, turmas com número elevado de alunos, aulas em séries diferentes, que exige muita motivação por parte do mesmo que passa a maior parte do tempo em pé. $O$ perfil do professor é o jovem brilhante, de boa aparência, paciente e verdadeiro "papagaio" em sala de aula.

\section{Considerações finais}

Guardadas as devidas proporções, o trabalho dos professores aqui estudado se encontra no âmbito da manufatura. $O$ desenvolvimento técnico não subordinou completamente o trabalhador ao capital; embora a divisão do trabalho tenha mutilado o domínio sobre o processo de trabalho, o professor ainda é um agente ativo na produção. Por mais que a racionalidade do capital tenha penetrado a escola-empresa, o docente não pode ser substituído pela máquina. No entanto, o professor não é mais um trabalhador-inte- 
lectual na acepção da palavra, que cria e prepara cursos específicos para seus alunos e detém um conhecimento abrangente de sua matéria. Temos sim, ao invés, um trabalhador parcelar inscrito na fragmentação de sua atividade, que mais do que nunca se restringe à reprodução de conhecimentos e informações presentes nas apostilas. Embora não esteja eliminada a subjetividade do trabalho no processo produtivo docente, são cada vez maiores as técnicas de obtenção de uma objetividade centradas na concorrência do mercado de trabalho, na aprovação dos alunos nas melhores universidades, e na própria expansão do sistema privado de ensino. Estudar a desqualificação do trabalho docente implica apreender como a dinâmica capitalista norteia o funcionamento dessas escolas-empresa. Podemos constatar que tais instituições operam em moldes empresariais e as determinações da gerência científica incidem diretamente no processo produtivo. O professor, neste caso, é um proletário e está sujeito a todas as vicissitudes do mercado de trabalho. A escola privada está conectada também com outro mercado, constituído pelos softwares, gráficas, editoras; redes de alimentação, universidades, etc., enfim, investindo em áreas cada vez mais diversificadas. Essa constatação corrobora a idéia de uma generalização da indústria e o próprio crescimento do setor de serviços, articulados com a história do desenvolvimento capitalista. Por mais cindida e mutilada que esteja a atividade docente, o elemento subjetivo ainda prevalece, a maquinaria não prescinde do profissional; o trabalho do professor depende, em última instância, de sua destreza, ainda que as condições objetivas da produção material imponham um ritmo que limita cada vez mais o desenvolvimento de suas potencialidades. 